Н. А. Звягинцева

Байкальский государственный университет, г. Иркутск, Российская Федерация

А. М. Парфенова

Байкальский государственный университет,

г. Иркутск, Российкая Федерация

\title{
КЛЮЧЕВЫЕ ПРОБЛЕМЫ ПРИВЛЕЧЕНИЯ СБЕРЕЖЕНИЙ ФИЗИЧЕСКИХ ЛИЦ ЧЕРЕЗ МЕХАНИЗМ РЫНКА ЦЕННЫХ БУМАГ
}

\begin{abstract}
АНнотАЦия. Активизация финансового рынка является одним из приоритетных направлений инновационного сценария развития экономики Российской Федерации. Практически полное закрытие доступа к внешним источникам финансирования вследствие введения экономических санкций в отношении России и снижения цен на сырье заставляют обратить пристальное внимание на внутренние источники финансирования инвестиционной деятельности. В результате задача по стимулированию внутреннего инвестора и созданию благоприятных условий для его деятельности на финансовом рынке выходит на первый план. В статье изучаются основные проблемы, препятствующие использованию рынка ценных бумаг для трансформации сбережений физических лиц в инвестиции. Приводятся мнения различных отечественных авторов на проблематику использования современного фондового рынка России, как механизма привлечения инвестиций. Рассматриваются возможные пути решения существующих сложностей и меры по стимулированию инвестиционной активности физических лиц на российском рынке ценных бумаг.

кЛЮЧЕВЫЕ СЛОВА. Рынок ценных бумаг; сбережения физических лиц; инвестиции; частные инвесторы; финансовые инструменты; ценные бумаги.

ИНФОРМАЦИЯ О СТАТЬЕ. Дата поступления 20 июня 2016 г.; дата принятия к печати 8 июля 2016 г.; дата онлайн-размещения 30 сентября 2016 г.
\end{abstract}

N. A. Zvyagintseva Baikal State University, Irkutsk, Russian Federation

A. M. Parfenova

Baikal State University, Irkutsk, Russian Federation

\section{KEY ISSUES OF ATTRACTING SAVINGS OF INDIVIDUALS THROUGH MECHANISM OF SECURITIES MARKET}

ABSTRACT. Activation of the financial market is one of the priority directions of innovative scenario for Russia's economic development. Practically complete closure of access to external sources of financing as a result of imposing economic sanctions against Russia and price-cutting of mineral resources are forcing to pay close attention to domestic sources of investment activity financing. As a result, the task of stimulating domestic investors and creating favorable conditions for their activities on the financial market moves to the forefront. The article investigates the main problems impeding using the securities market for the transforming individuals' savings into investments. It cites opinions of various domestic authors on the problems of using Russia's modern stock market as a mechanism for attracting investments. It considers possible ways of solving the existing complexity and measures of stimulating investment efforts of individuals on Russia's securities market.

KEYWORDS. Securities market; savings of individuals; investments; private investors; financial instruments; securities.

ARTICLE INFO. Received June 20, 2016; accepted July 8, 2016; available online September $30,2016$.

(ㄷ) Н.А. Звягинцева, А. М. Парфенова, 2016

\section{Baikal Research Journal}


В современных условиях, сопровождающихся обострением геополитической ситуации, одной из основных для экономики России становится проблема невозможности привлечения иностранного капитала. Поэтому актуальность вопроса мобилизации внутренних финансовых ресурсов, в частности, через механизм рынка ценных бумаг, как никогда велика.

Рынок ценных бумаг играет роль основного инструмента в привлечении средств в производство, мобилизации ресурсов на восстановление и развитие экономики, финансировании дефицита государственного бюджета [1, с. 144]. Рынок ценных бумаг играет важную роль в системе перераспределения финансовых ресурсов государства, а также он необходим для нормального функционирования рыночной экономики [2, с. 48]. Рынок ценных бумаг выполняет регулирующие функции финансовых ресурсов, перетока капитала в отрасли или из одного региона в другой, обеспечивающие наибольшую рентабельность вложения, он четко реагирует на происходящие и предполагаемые изменения в социально-экономической и иной жизни общества [3, с. 440].

Внутренние источники долгосрочных инвестиций - это в первую очередь сбережения населения. Данные обстоятельства порождают ряд вопросов. В частности, насколько емкими являются данные источники и способен ли российский рынок ценных бумаг в полной мере их поглотить для дальнейшей трансформации в инвестиции. Для оценки инвестиционного потенциала физических лиц целесообразно провести динамический анализ источников формирования сбережений населения (табл. 1), а также исследовать пути их использования.

Объем и структура денежных доходов населения по источникам поступления за 2012-2015 г2., \%

\begin{tabular}{|l|r|r|r|r|r|r|}
\hline \multicolumn{1}{|c|}{ Денежные доходы } & \multicolumn{1}{|c|}{2012} & \multicolumn{2}{|c|}{2013} & 2014 & \multicolumn{3}{|c|}{2015} \\
\cline { 5 - 8 } & & & & I кв. & \multicolumn{1}{c|}{ II кв. } & \multicolumn{1}{c|}{ III кв. } \\
\hline $\begin{array}{l}\text { Доходы от предпринимательской } \\
\text { деятельности }\end{array}$ & 9,4 & 8,6 & 7,8 & 7,9 & 7,1 & 7,6 \\
\hline $\begin{array}{l}\text { Оплата труда, включая скрытую } \\
\text { заработную плату }\end{array}$ & 65,1 & 65,3 & 66,7 & 66,4 & 65,8 & 65,3 \\
\hline Социальные выплаты & 18,4 & 18,6 & 18,2 & 18,0 & 18,8 & 18,4 \\
\hline Доходы от собственности & 5,1 & 5,5 & 5,3 & 5,7 & 6,3 & 6,7 \\
\hline Другие доходы & 2,0 & 2,0 & 2,0 & 2,0 & 2,0 & 2,0 \\
\hline Всего, млрд р. & 39903,7 & 44650,4 & 46540,3 & 11167,5 & 13029,6 & 13389,8 \\
\hline
\end{tabular}

Источник: Доходы и расходы населения [Электронный ресурс] // Федеральная служба государственной статистики : офиц. сайт. Режим доступа : http://www.gks.ru/wps/wcm/connect/rosstat_main/ rosstat/ru/statistics/population/level/\#.

Из приведенных данных видно, что абсолютный объем денежных доходов населения увеличивается. Однако очевидно, что этот рост номинальный: в связи с усилением инфляционных процессов реальные доходы населения имеют тенденцию к сокращению ${ }^{1}$.

Структура денежных доходов населения за рассматриваемый период оставалась практически неизменной. Наибольшая доля приходится на оплату труда, в том числе включая скрытую заработную плату. Значительный удельный вес занимают денежные доходы от социальных выплат.

Из данных о структуре использования денежных доходов физических лиц (табл. 2) следует, что основную долю в структуре использования денежных дохо-

${ }^{1}$ Справочно: среднегодовой темп инфляции в 2012 г. составил 6, 58 \% , 2013 г. — 6, 45 \% , 2014 г. $11,36 \%, 2015$ г. $-12,91 \%$.

\section{Baikal Research Journal}

электронный научный журнал Байкальского государственного университета 
дов физических лиц закономерно занимают расходы на покупку товаров и оплату услуг. Доля сбережений в структуре использованных денежных доходов в 2013-2014 гг. оставалась практически неизменной на уровне порядка 9 \% . В то время, как доля вложений в иностранную валюту в 2014 г. закономерно увеличилась вследствие существенной девальвации национальной валюты и высокой волатильности валютного рынка.

Таблица 2

Структура использования денежных доходов населения за 2012-2015 г2., \%

\begin{tabular}{|l|r|r|r|r|r|r|}
\hline \multicolumn{1}{|c|}{ Использованные доходы } & 2012 & 2013 & 2014 & \multicolumn{3}{|c|}{2015} \\
\cline { 4 - 7 } & & & & I кв. & II кв. & III кв. \\
\hline Покупка товаров и оплата услуг & 78,3 & 73,6 & 75,3 & 78,2 & 70,8 & 73,2 \\
\hline Оплата обязательных платежей и взносов & 11,1 & 11,7 & 11,8 & 11,0 & 10,6 & 11,1 \\
\hline Сбережения & 10,0 & 9,8 & 8,5 & 13,1 & 14,2 & 11,3 \\
\hline Покупка валюты & 3,7 & 4,2 & 7,1 & 4,1 & 4,1 & 4,8 \\
\hline Прирост / уменьшение тезаврации & $-3,1$ & 0,7 & 0,5 & $-6,4$ & 0,3 & $-0,4$ \\
\hline
\end{tabular}

Источник: Доходы и расходы населения [Электронный ресурс] // Федеральная служба государственной статистики : офиц. сайт. Режим доступа : http://www.gks.ru/wps/wcm/connect/rosstat_main/ rosstat/ru/statistics/population/level/\#.

Структура использования денежных доходов населения претерпела значительные изменения в 2015 г.: в первой половине года наблюдалось усиление склонности населения к сбережению. Данная тенденция связана с событиями в конце 2014 г.: резкое ослабление национальной валюты, увеличение ключевой ставки до 17 \% , падение цен на нефть. Данные факторы в связи с неустойчивостью экономики вынудили население активно сберегать свои средства.

Исследуя пути использования сбережений физических лиц, Ю. Данилов отмечает, что в настоящий момент существует два основных потока вложения сбережений физических лиц, которые практически неизменны на протяжении последних десяти лет. Первый поток - инвестиции в недвижимость; второй поток - прирост банковских вкладов, преимущественно кратко- и среднесрочных, сменяющийся в периоды кризисов покупкой иностранной валюты [4, с. 32].

В рамках сложившейся в России модели перераспределения сбережений физических лиц инвестирование через механизмы рынка ценных бумаг остается незначительным дополнением к двум основным потокам вложения сбережений. Между тем, именно данная часть сбережений частных инвесторов за рубежом является основой для формирования долгосрочных вложений. Так, из приведенных данных о составе и структуре сбережений населения во вкладах и ценных бумагах за 2012-2015 гг. (табл. 3) можно сделать вывод о росте объема инвестирования сбережений населения, выраженного в абсолютных значениях. При этом доля вложений денежных средств в ценные бумаги значительно меньше, чем размещение средств во вкладах, но удельный вес данного направления вложения сбережений населения демонстрирует тенденцию к росту.

C точки зрения мирового опыта доля сбережений физических лиц, вкладываемых в недвижимость, иностранную валюту или на краткосрочные банковские депозиты в России, сильно завышена, а доля сбережений, инвестируемых через институты коллективного инвестирования или напрямую в долгосрочные ценные бумаги российских корпораций, крайне мала. Именно поэтому дефицит собственного капитала у российских компаний есть обратная сторона неэффективного использования сбережений населения [4, с. 32].

В настоящее время российскими учеными, разрабатывающими проблематику развития рынка ценных бумаг, выделяются различные факторы, препятствующие

\section{Baikal Research Journal}

электронный научный журнал Байкальского государственного университета 
использованию рынка ценных бумаг, как эффективного перераспределительного механизма. Приведем некоторые существующие точки зрения.

Состав и структура сбережений населения во вкладах и ценных бумагах Таблица 3 за 2012-2015 г2., млрдр.

\begin{tabular}{|c|c|c|c|c|c|c|c|c|}
\hline \multirow[t]{2}{*}{ Показатель } & \multicolumn{2}{|c|}{2012} & \multicolumn{2}{|c|}{2013} & \multicolumn{2}{|c|}{2014} & \multicolumn{2}{|c|}{2015} \\
\hline & Сумма & $\begin{array}{c}\text { Удель- } \\
\text { ный } \\
\text { вес }\end{array}$ & Сумма & $\begin{array}{c}\text { Удель- } \\
\text { ный } \\
\text { вес }\end{array}$ & Сумма & $\begin{array}{c}\text { Удель- } \\
\text { ный } \\
\text { вес }\end{array}$ & Сумма & $\begin{array}{l}\text { Удель- } \\
\text { ный } \\
\text { вес }\end{array}$ \\
\hline $\begin{array}{l}\text { Сбережения во } \\
\text { вкладах и ценных } \\
\text { бумагах }\end{array}$ & 1613979 & 100 & 1870067 & 100 & 2467141 & 100 & 2248651 & 100 \\
\hline $\begin{array}{l}\text { В том числе: } \\
\text { Прирост (уменьше- } \\
\text { ние) вкладов в ком- } \\
\text { мерческие банки }\end{array}$ & 1537305 & 5,2 & 1781137 & 95,2 & 2052506 & 3,2 & 1907669 & 4,8 \\
\hline $\begin{array}{l}\text { Приобретение } \\
\text { государственных } \\
\text { и других ценных } \\
\text { бумаг }\end{array}$ & 76674 & 4,8 & 88930 & 4,8 & 414635 & 6,8 & 340982 & 5,2 \\
\hline
\end{tabular}

Источник: Доходы и расходы населения [Электронный ресурс] // Федеральная служба государственной статистики : офиц. сайт. Режим доступа : http://www.gks.ru/wps/wcm/connect/rosstat_main/ rosstat/ru/statistics/population/level/\#.

Р. А. Смирнов среди главных проблем развития российского рынка ценных бумаг выделяет организационные, кадровые и методологические недостатки. Организационные проблемы связаны с отсутствием развитой инфраструктуры рынка и слабым информационным обеспечением, что создает «среду неопределенности» для физических лиц при принятии инвестиционных решений о направления вложения собственных сбережений. Кадровые проблемы предопределены малым сроком развития рынка ценных бумаг и недостаточным числом высокопрофессиональных специалистов. Методологические же проблемы вызваны непроработанностью методик осуществления многих фондовых операций и отдельных процедур на рынке ценных бумаг [5, с. 8].

Проблемы развития рынка ценных бумаг, как инвестиционного механизма, автор также связывает со следующими процессами:

- отсутствие современной системы центров клиринговых расчетов, депозитариев, независимых регистраторов, обеспечивающих информационную «прозрачность» рынка для всех участников и соответствующую мировым стандартам;

- юридическая неподготовленность к заключению договоров с партнерами с учетом возможных убытков от неожиданных изменений на рынке и надежности партнеров с точки зрения их платежеспособности;

- отсутствие единых, соответствующих мировым стандартам общероссийских классификаторов операций, технологий банков и бирж;

- несоответствие действующих форм бухгалтерского учета международным стандартам [5, с. 9].

Следствием же является недостаточный объем финансирования экономики с помощью инструментов фондового рынка (в России - менее 6 \%, тогда как в странах с развитой рыночной экономикой - до 80 \%) и незначительная доля реального капитала на финансовом рынке.

Л. А. Куликова определяет следующие основные причины, тормозящие выход физических лиц на российский фондовый рынок. Первая причина - схожесть продуктов, предлагаемых российскими инвестиционными фондами, что не позволяет

\section{Baikal Research Journal}


создать разнообразную продуктовую линейку, удовлетворяющую разные категории потенциальных частных инвесторов. Остаются немногочисленными попытки разработки эксклюзивных продуктов, а соответственно не происходит усиление конкурентной борьбы за частного инвестора. Такое поведение институтов коллективного инвестирования не способствует привлечению массового инвестора на фондовый рынок. Вторая причина - в России пока отсутствует институт независимых инвестиционных консультантов. А ведь именно они в странах с более развитой экономикой способствуют продвижению инвестиционных продуктов (например, в США более 50 \% продаж таких продуктов, в том числе физическим лицам, происходит через инвестиционных консультантов). Другими словами, на российском рынке есть больной (в лице инвестора), есть аптекарь (в лице брокера), но нет доктора. Больной идет напрямую к аптекарю, и аптекарь дает ему то, что имеет, а не то, что посоветовал бы доктор [6, с. 72].

По мнению А. М. Багдасарян, в России, как и в других странах с переходной экономикой, для дальнейшего развития рынка ценных бумаг необходимо уделять внимание решению многих проблем, в частности увеличению объема капитала, направляемого на рынок ценных бумаг, увеличению инвестиционных возможностей, развитию и интеграции торговых, расчетно-клиринговых и депозитарных систем рынка ценных бумаг и повышению осведомленности потенциальных участников рынка ценных бумаг, в том числе физических лиц, о возможностях рынка [7, с. 124].

В целях равномерной диверсификации направлений инвестирования сбережений населения между банковской сферой и рынком ценных бумаг следует привести в соответствие конкурентное положение фондового рынка. Для этого требуется реализовать следующие мероприятия.

Необходимо кардинально повысить доверие населения к институтам коллективного инвестирования и профессиональным участникам рынка ценных бумаг за счет создания общенациональной компенсационной системы. Такая система должна быть создана в значительной мере по аналогии с системой страхования вкладов, т. е. участники рынка должны за счет своих взносов сформировать компенсационные фонды, а государство, стимулируя и принуждая участников рынка «делать взносы», одновременно выступало бы в качестве кредитора последней инстанции по отношению к частным компенсационным фондам. В 1995 г. с целью осуществления компенсационных выплат лицам, которым был причинен ущерб на фондовом рынке РФ, был создан Федеральный общественно-государственный фонд по защите прав вкладчиков и акционеров . Несмотря на то, что указанный фонд действует на государственном уровне, о его деятельности практически ничего не известно. Это связано с ограничениями по размеру максимальной выплаты, по перечню лиц, имеющих право получить компенсацию и т. д. В связи с этим, деятельность Федерального общественно-государственного фонда по защите прав вкладчиков и акционеров в качестве компенсационного органа не является действенной: права частных инвесторов защищаются в малом объеме, а под категорию тех вкладчиков, которые могут иметь право на компенсацию, подпадает очень узкий круг лиц.

По мнению С. А. Минлигареевой, доверие частных инвесторов к рынку ценных бумаг повысится вследствие создания унифицированной системы показателей для оценки рынка ценных бумаг, введения компетентной рейтинговой оценки компаний-эмитентов и развития специализированных изданий, освещающих отдельные отрасли как объекты для инвестиций [8, с. 129]. Мерой защиты прав и интересов инвесторов и в целях предоставления достоверной информации на рынке ценных бумаг может послужить создание так называемых ярлыков или информационных знаков, которые финансовые организации должны в обязательном порядке размещать на рекламе финансовых продуктов, представляющих повышенный риск для инвесторов.

\section{Baikal Research Journal}

электронный научный журнал Байкальского государственного университета 
Достоверность предоставляемой клиентам (частным инвесторам) информации важна как в процессе принятия решений, так и при определении объема и структуры последующих инвестиций. Здесь решающим фактором будет совпадение полученной информации и результатов инвестирования. Даже если был получен отрицательный результат от инвестирования, но инвестор был проинформирован - это не вызовет негативного отношения, как понимание того, что он был введен в заблуждение.

Банк России для обеспечения надлежащего уровня защиты прав потребителей финансовых услуг планирует создание и запуск в эксплуатацию более эффективной системы работы с поступающими жалобами. Совокупность созданных мер предполагает организацию работы таким образом, что число обращений, по которым оказана фактическая помощь, существенно увеличится, а также будут сокращены сроки принятия мер реагирования и оптимизирован процесс взаимодействия с органами власти и организациями при работе с обращениями потребителей финансовых услуг.

Для стимуляции активности частных инвесторов на рынке ценных бумаг необходимо повысить уровень финансовой грамотности населения. В настоящее время серьезной проблемой, препятствующей как развитию российского фондового рынка, так и удовлетворенности населения продуктами и услугами рынка ценных бумаг, является недостаточный уровень финансовой грамотности населения. Поскольку повышение финансовой грамотности населения является долгосрочной задачей, в среднесрочном периоде предложение населению доступных для понимания финансовых продуктов и услуг может быть обеспечено за счет их стандартизации, в том числе договорной базы. Это будет способствовать как повышению общего уровня информированности граждан о финансовом рынке, так и росту уровня доверия населения $\kappa$ финансовым инструментам. Первым шагом на пути решения указанной задачи является введение Министерством образования и науки РФ с 2016 г. модуля по финансовой грамотности в обязательную школьную программу по предмету «обществознание».

Еще одним направлением активизации использования механизма рынка ценных бумаг для привлечения сбережений физических лиц является повышение доступности финансовых инструментов и услуг для широких масс населения во всех регионах России. Для повышения уровня доступности финансовых услуг необходимо прежде всего создать условия для развития региональных компаний-поставщиков финансовых услуг. При совершенствовании системы доступа к продуктам и услугам фондового рынка рынка важно одновременно обеспечить их востребованность и полезность для потребителей. На рынке ценных бумаг должны быть представлены понятные потребителю финансовые продукты и услуги, чтобы гражданин имел возможность оценить степень их положительного, либо отрицательного влияния на удовлетворение своих потребностей и качество жизни.

Задача вовлечения средств населения в инвестиционный оборот может быть облегчена, если учесть фактор неравномерного распределения потенциальных источников инвестирования. Во-первых, свободные инвестиции населения неоднородны в региональном отношении. Во-вторых, свободными денежными средствами обладает относительно небольшая по численности прослойка населения [9, с. 47].

На современном этапе уже введена в действие одна из мер стимулирования привлечения средств частных инвесторов на рынок ценных бумаг. Речь идет о создании Института индивидуальных инвестиционных счетов (ИИС). В 2015 г. вступили в силу законодательные новации, позволяющие частному инвестору использовать льготы при уплате налога на доходы физических лиц в части доходов от операций с ценными бумагами. В условиях действующего законодательства инвестиции в ценные бумаги являются менее привлекательными с налоговой точки зрения, чем другие виды инвестиций (в том числе, депозиты в кредитных организациях). В целях выравнивания налоговых условий для инвестиций населения в различные виды

\section{Baikal Research Journal}

электронный научный журнал Байкальского государственного университета 
активов, в законодательство о ценных бумагах было включено понятие «индивидуальный инвестиционный счет», а также требования к осуществлению профессиональной деятельности на рынке ценных бумаг, связанных с управлением ИИС, а также введен инвестиционный налоговый вычет [10, с. 40].

В 2016 г. Банком России опубликован первый в своем роде документ, касающийся целенаправленного совершенствования функционирования финансового рынка и рынка ценных бумаг - Основные направления развития финансового рынка Российской Федерации на период 2016-2018 гг. В этом документе Банк России выделил три приоритетные цели развития российского финансового рынка:

1. Повышение уровня и качества жизни граждан Российской Федерации за счет использования инструментов финансового рынка.

2. Содействие экономическому росту за счет предоставления конкурентного доступа субъектам российской экономики к долговому и долевому финансированию, инструментам страхования рисков.

3. Создание условий для роста финансовой индустрии.

Для достижения указанных целей Банк России определил мероприятия, реализацию которых необходимо осуществить в течение 2016-2018 гг. и, частично, в долгосрочной перспективе. Данные мероприятия сгруппированы по десяти основным направлениям развития финансового рынка, реализация которых позволит активизировать вовлечение средств населения для целей финансирования инвестиций через механизмы рынка ценных бумаг. К ним, в частности, относятся:

- обеспечение защиты прав потребителей финансовых услуг и повышение финансовой грамотности населения России;

- повышение доступности финансовых услуг для населения и субъектов малого и среднего предпринимательства;

- дестимулирование недобросовестного поведения на финансовом рынке ${ }^{2}$.

Выявлено также, что на рынке ценных бумаг недостаточна доля привлеченных средств, инвестированных впоследствии именно в основной капитал. Значительная часть финансовых поступлений направляется на рефинансирование долговой нагрузки и приобретение долей участия в компаниях [11, с. 12].

Итак, без инвестиционно направленного рынка ценных бумаг не может быть эффективной экономической системы. Именно инвестиционно направленный фондовый рынок может обеспечить увеличение темпов роста экономики, создав необходимые условия для финансирования экономического развития [12, с. 184].

Таким образом, проблема привлечения сбережений населения в настоящий момент остается по-прежнему актуальной: на данный момент все еще отсутствует благоприятная среда для трансформации сбережений физических лиц в инвестиции, поступающие в реальный сектор экономики через рынок ценных бумаг. В сложившейся непростой экономической ситуации государственные регуляторы стали осознавать важность роли финансового рынка, а также перспективы, которые могут быть достигнуты в результате использования его неосвоенного потенциала. Поэтому мегарегулятор в лице Банка России активно определяет основные направления модернизации рынка ценных бумаг. Данные преобразования нацелены на улучшение условий и повышение эргономичности рынка, рост доступности финансовых услуг и финансовых инструментов, дальнейшее развитие удобной для частного инвестора инфраструктуры, повышение защищенности интересов инвесторов и т. д. Таким образом, можно сделать вывод о том, что, возможно, экономический кризис может стать хорошим катализатором для начала системных и масштабных изменений на рынке ценных бумаг. Так это или нет можно будет оценить уже совсем скоро.

${ }^{2}$ Федеральный общественно-государственный фонд по защите вкладчиков и акционеров : офиц. сайт. URL : http://www.fedfond.ru/about/.

\section{Baikal Research Journal}

электронный научный журнал Байкальского государственного университета 


\section{Список использованной литературы}

1. Хутаев Р. Н. Место рынка ценных бумаг в финансовых рынках РФ / Р. Н. Хутаев, P. М. Мансуров // Вопросы образования науки: теоретический и методический аспекты : сб. науч. тр. по материалам Международной научно-практической конференции. - Тамбов : Консалтинг. компания Юком, 2015. - С. 144-145.

2. Балалова Е. И. Место и роль рынка ценных бумаг в системе финансовых рынков / Е. И. Балалова // Фундаментальные и прикладные исследования кооперативного сектора экономики. - 2014. - № 4. - С. 48-52.

3. Хубулава Н. М. Инвестиционная деятельность в условиях девальвации курса рубля / Н. М. Хубулава, В. Г. Ларионов, В. В. Юдина // Известия Иркутской государственной экономической академии. - 2015. - № 3. - C. 435-442. - DOI : 10.17150/19933541.2015.25(3).435-442.

4. Данилов Ю. Пробить новое русло / Ю. Данилов // Вестник НАУФОР. - 2011. № 8. - С. 31-33.

5. Смирнов Р. А. Проблемы и перспективы развития рынка ценных бумаг в РФ / Р. А. Смирнов // Вестник Горного университета. - 2015. - № 6. - С. 2-19.

6. Куликова Л. А. Проблема привлечения индивидуальных инвесторов на рынок ценных бумаг / Л. А. Куликова // Инновационная наука. - 2015. — № 4. - С. 71-72.

7. Багдасарян А. М. Проблемы развития рынка ценных бумаг в странах с переходной экономикой / А. М. Багдасарян // Вестник Ленинградского государственного университета им. А. С. Пушкина. - 2012. - № 1. - С. 115-125.

8. Минлигареева С. А. Проблемы и пути совершенствования государственного регулирования рынка ценных бумаг / С. А. Минлигареева / Science Time. - 2014. — № 6. - С. $122-131$.

9. Звягинцева Н. А. Оценка инвестиционного потенциала физических лиц и путей его реализации через механизмы рынка ценных бумаг в РФ / Н. А. Звягинцева // Вестник Алтайской академии экономики и права. - 2014. - № 3. - С. 44-49.

10. Роднина А. Ю. К теории сбережений / А. Ю. Роднина, Т. М. Корягина, Б. Д. Бабаев // Теоретическая экономика. - 2013. - № 1. - С. 38-42.

11. Бадилина Л. П. Активизация инвестиционных процессов в Российской Федерации с использованием рынка ценных бумаг / Л. П. Бадилина, Н. А. Звягинцева / Известия Иркутской государственной экономической академии. -2016 . - T. 26, № 1. - C. 5-14. - DOI : 10.17150/1993-3541.2016.26(1).5-14.

12. Звягинцева Н. А. Использование механизмов защиты прав инвесторов для развития инвестиционно направленного рынка ценных бумаг / Н. А. Звягинцева. - Иркутск : Изд-во БГУЭП, 2010. - 259 с.

\section{References}

1. Khutayev R. N., Mansurov R. M. Place of securities market on financial markets of the Russian Federation. Voprosy obrazovaniya nauki: teoreticheskii i metodicheskii aspekty. Materialy Mezhdunarodnoi nauchno-prakticheskoi konferentsii [Issue of developing science: theoretical and methodical aspects . Materials of International Research Conference]. Tambov, Consulting Company Yukom Publ., 2015, pp. 144-145. (In Russian).

2. Balalova E. I. Place and role of securities market in system of financial markets. Funda mental'nye i prikladnye issledovaniya kooperativnogo sektora ekonomiki = Fundamental and Applied Studies of Cooperative Sector of Economics, 2014, no. 4, pp. 48-52. (In Russian).

3. Hubulava N. M., Larionov V. G., Yudina V. V. Investment activity in the conditions of ruble devaluation. Izvestiya Irkutskoy gosudarstvennoy ekonomicheskoy akademii = Bulletin of Irkutsk State Economics Academy, 2015, vol. 25, no. 3, pp. 435-442. DOI: 10.17150/19933541.2015.25(3).435-442. (In Russian).

4. Danilov Yu. Breaking through the new corridor. Vestnik NAUFOR=Bulletin of NAUFOR, 2011, no. 8, pp. 31-33. (In Russian).

5. Smirnov R. A. Problems and Prospects of Developing Securities Market of the Russian Federation. Vestnik Gornogo universiteta = Bulletin of Mining University, 2015, no. 6, pp. 2-19. (In Russian).

6. Kulikova L. A. Problem of attracting individual investors to securities market. Innovat sionnaya nauka = Innovative Science, 2015, no. 4, pp. 71-72. (In Russian).

\section{Baikal Research Journal}


7. Bagdasaryan A. M. Problems of development of the equity market in the countries with transition economy. Vestnik Leningradskogo gosudarstvennogo universiteta imeni A. S. Pushki$n a=$ A.S. Pushkin Bulletin of Leningrad State University, 2012, no. 1, pp. 115-125. (In Russian).

8. Minligareyeva S. A. Problems and ways of improving governmental regulation of securities market. Science Time, 2014, no. 6, pp. 122-131. (In Russian).

9. Zvyagintseva N. A. Assessment of investment potential of individuals and ways of its implementation through the mechanisms of securities market in Russia. Vestnik Altaiskoi akademii ekonomiki i prava = Journal of Altai Academy of Economics and Law, 2014, no. 3, pp. 44-49. (In Russian).

10. Rodnina A. Yu., Koryagina T. M., Babaev B. D. On Theory of Savings. Teoreticheskaya ekonomika = Theoretical Economy, 2013, no. 1, pp. 38-42. (In Russian).

11. Badilina L. P., Zvyagintseva N. A. Enhancing investment processes in the Russian Federation through the securities market. Izvestiya Irkutskoy gosudarstvennoy ekonomicheskoy akademii $=$ Bulletin of Irkutsk State Economics Academy, 2016, vol. 26, no. 1, pp. 5-14. DOI: 10.17150/1993-3541.2016.26(1).5-14. (In Russian).

12. Zvyagintseva N. A. Ispol'zovanie mekhanizmov zashchity prav investorov dlya razvitiya investitsionno napravlennogo rynka tsennykh bumag [Using mechanisms of protecting investors' rights for developing investment-oriented securities market]. Irkutsk, Baikal State University of Economics and Law Publ., 2010. 259 p. (In Russian).

\section{Информация об авторах}

Звягинцева Наталья Александровна - доктор экономических наук, профессор, кафедра банковского дела и ценных бумаг, Байкальский государственный университет, 664003, г. Иркутск, ул. Ленина, 11, e-mail: legnata2010@yandex.ru.

Парфенова Анаит Месроповна - магистрант, кафедра банковского дела и ценных бумаг, Байкальский государственный университет, 664003, г. Иркутск, ул. Ленина, 11, e-mail: anait1762@mail.ru.

\section{Библиографическое описание статьи}

Звягинцева Н. А. Ключевые проблемы привлечения сбережений физических лиц через механизм рынка ценных бумаг / Н. А. Звягинцева, А. М. Парфенова // Baikal Research Journal. — 2016. — T. 7, № 5. — DOI : 10.17150/2411-6262.2016.7(5).1.

\section{Authors}

Nataly A. Zvyagintseva - Doctor habil. (Economics), Professor, Chair of Banking and Securities, Baikal State University, 11 Lenin St., 664003, Irkutsk, Russian Federation; e-mail: legnata2010@yandex.ru.

Anait M. Mesropovna - Master Degree Student, Chair of Banking and Securities, Baikal State University, 11 Lenin St., 664003, Irkutsk, Russian Federation; e-mail: anait1762@mail.ru.

\section{Reference to article}

Zvyagintseva N. A., Parfenova A. M. Key issues of attracting savings of individuals through mechanism of securities market. Baikal Research Journal, 2016, vol. 7, no. 5. DOI : 10.17150/2411-6262.2016.7(5).1. (In Russian).

\section{Baikal Research Journal}

